\title{
Prevalence of the anatomical variations of concha bullosa and its relation with sinusitis among Saudi population: a computed tomography scan study
}

\author{
Wael Amin Nasr El-Din ${ }^{1,2}$, Gisma Ahmed Madani ${ }^{3}$, Islam Omar Abdel Fattah ${ }^{2}$, Esmat Mahmoud ${ }^{4,5}$, \\ Asmaa S. Essawy ${ }^{6,7}$ \\ ${ }^{1}$ Department of Anatomy, College of Medicine and Medical Sciences, Arabian Gulf University, Manama, Bahrain, ${ }^{2}$ Department of Human Anatomy \\ and Embryology, Faculty of Medicine, Suez Canal University, Ismailia, Egypt, ${ }^{3}$ Department of Anatomy, Faculty of Medicine, The National University, \\ Khartoum, Sudan, ${ }^{4}$ Department of Radiology, National Cancer Institute (NCI), Cairo University, Cairo, Egypt, ${ }^{5}$ Department of Medical Imaging, \\ Saudi German Hospitals Group, Jeddah, Saudi Arabia, ${ }^{6}$ Department of Human Anatomy and Embryology, Faculty of Medicine, Menoufia University, \\ Menoufia, Egypt, ${ }^{7}$ Department of Anatomy, Ibn Sina National College for Medical Studies, Jeddah, Saudi Arabia
}

\begin{abstract}
Concha bullosa (CB) is a pneumatic cavitation inside a concha in the nasal cavity. It is one of the most widely recognized nasal variations and is mostly found in the middle concha. $\mathrm{CB}$ is divided according to its site into three types; lamellar, bulbous and extensive. The goal of our study was to estimate the prevalence of CB among Saudi adult population and its association with sinusitis by using multidetector computed tomography (MDCT). This was a retrospective study carried out over a three-year period on 879 adult Saudi patients aged 18 years or older, referred for MDCT assessment of paranasal sinuses. Males were 540 and females were 339. Patients with facial congenital anomalies or nasal trauma were excluded from our study. CB was prevalent in both males and females among Saudi population (55.4\%, 55.7\%) respectively. Bilateral CB (55.5\%) was more frequent than unilateral (44.5\%). Extensive CB (44.0\%) was the most frequent type. Sinusitis was associated more in patients with $\mathrm{CB}(48.0 \%)$ versus those who have no $\mathrm{CB}(5.9 \%)$. In conclusion, $\mathrm{CB}$ was prevalent among Saudi population and the most frequently recorded is the extensive type. Furthermore, the most common type associated with sinusitis was extensive CB (49.6\%).
\end{abstract}

Key words: Concha bullosa, Multidetector computed tomography, Saudi population, Sinusitis

Received September 17, 2020; Revised November 13, 2020; Accepted December 4, 2020

\section{Introduction}

The middle concha of the nasal cavity is a flat bone, if a pneumatic expansion from anterior ethmoid cells or less commonly from posterior cells invades the bone, it is known

\section{Corresponding author:}

Wael Amin Nasr El-Din (iD

Department of Anatomy, College of Medicine and Medical Sciences, Arabian Gulf University, Manama 26671, Bahrain

E-mail:waelamin2010@yahoo.com as concha bullosa (CB) [1]. CB is considered as a common nasal anatomical variation and not referred as a disease. The middle concha is frequently affected by $\mathrm{CB}$, in contrast; the superior and inferior conchae are rarely affected [2]. The pneumatized middle concha is categorized into three groups based on the location of pneumatization site and extension: lamellar type is the vertical lamella pneumatization of the concha (Fig. 1A), bulbous type is the bulbous part pneumatization (Fig. 1B) and extensive $\mathrm{CB}$ is the pneumatization of both lamellar and bulbous segments (Fig. 1C) [1]. Frequently, the $\mathrm{CB}$ contains only one air cell, however numerous air cells

\section{Copyright (c) 2021. Anatomy \& Cell Biology}

This is an Open Access article distributed under the terms of the Creative Commons Attribution Non-Commercial License (http://creativecommons.org/licenses/by-nc/4.0/) which permits unrestricted non-commercial use, distribution, and reproduction in any medium, provided the original work is properly cited. 

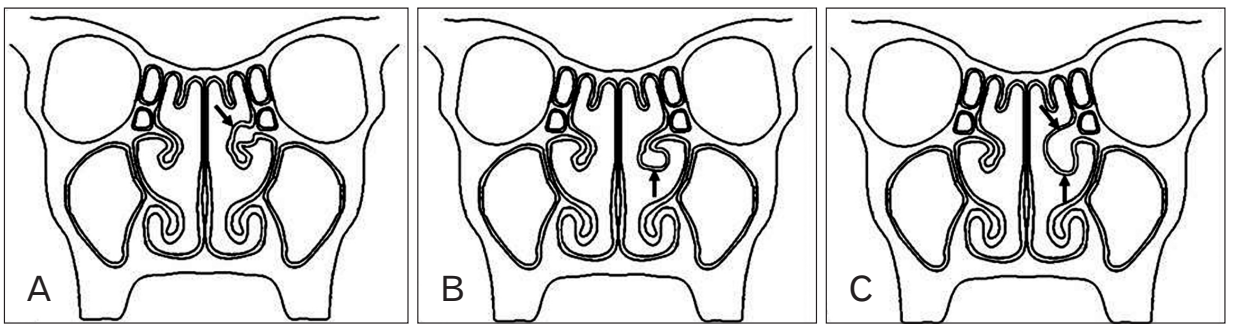

Fig. 1. Types of concha bullosa (arrows): (A) lamellar type, (B) bulbous type, and (C) extensive type. (Illustrated by Nasr El-Din et al.). within a CB are fairly uncommon [2].

The medial portion of the ethmoid bone forms the middle concha. Because of its expansion within the nasal cavity, anterior-superior stability is supported by the cribriform plate. The lamina papyracea is responsible for the posterior and lateral stability [3]. The epithelial lining of the nasal cavity prolongs to line the cavity of the $\mathrm{CB}$ so its cells may be attacked by the same inflammatory diseases of the paranasal sinuses. Moreover, mucocele formation may be the result of obstruction of the drainage of a CB [4].

$\mathrm{CB}$ has been involved as a potential risk factor in the recurrence of chronic sinusitis because it has a negative effect on the ventilation of paranasal sinuses and mucociliary clearance in the area of the middle meatus [5]. The mere presence of CB does not need any surgical intervention; however, its existence can lead to the osteomeatal complex (OMC) occlusion followed by sinus disorders [6].

OMC is the ultimate mutual route for the frontal, maxillary and anterior ethmoid air cells that allows their drainage and ventilation [7]. So, the occlusion of this narrow zone is a leading factor in the production of chronic sinusitis [5]. Deviated nasal septum, large bulla ethmoidalis, paradoxical middle turbinate and $\mathrm{CB}$ are anatomical variations that could participate to chronic rhinosinusitis pathogenesis by OMC blockage as a result of impeding the drainage of the anterior group of paranasal sinuses [4]. The purpose of the surgical procedures of the functional endoscopic sinus surgery is to get rid of the osteomeatal obstruction and to retrieve natural ventilation and mucociliary function of the sinuses [8].

Surgical intervention is not required in asymptomatic CB; however, medical treatment may be indicated to provide short-term symptomatic relief including antibiotics, topical steroids, antihistamines and topical nasal decongestants [9]. Nevertheless, nowadays many different surgical approaches for $\mathrm{CB}$ treatment are used, such as endoscopic lateral or medial partial resection, turbinoplasty, total resection, crushing and crushing with intrinsic stripping. However, there is no obvious consensus about which is the best surgical option yet [10].
Our study aimed to use the computed tomography (CT) scan imaging of the nasal cavity and paranasal sinuses to assess the prevalence of CB among adult Saudi population, compare the prevalence with other populations and its possible association with sinusitis.

\section{Materials and Methods}

\section{Study design}

A retrospective blinded study consisting of 879 subjects subjected to multidetector computed tomography (MDCT) imaging of their nasal cavity and paranasal sinuses region. The study was conducted at the Medical Imaging Department, Saudi German Hospitals Group, Jeddah, KSA, in the period between December 2016 and January 2020. MDCT was performed using a Lightspeed VCT 64 slice CT machine $(\mathrm{kVp}$ [kilo voltage peak] $=100$, MAs [Milli-Ampere seconds] $=200$, rotation time $=0.5$ second, FOV [field of view $]=240 \mathrm{~mm}$, slice thickness $=1.5 \mathrm{~mm}$, reconstruction interval $=0.5 \mathrm{~mm}$, pitch=1.375; GE, Milwaukee, WI, USA). The study was conducted according to the principles of the Declaration of Helsinki 1995 (as revised in 2013). The study was approved by Research Ethics Committee of Saudi German Group Hospitals (approval No. SGH-134/20/06/2016) in addition to obtaining informed consent from all subjects.

According to sex of the subjects, 540 (61.4\%) were males and $339(38.6 \%)$ were females. All subjects were Saudi adults aged 18 years or more. Subjects less than 18 years old, those with facial congenital anomalies or trauma of the nasal and paranasal sinuses region were excluded from this study.

Picture archiving and communication system was utilized to evaluate the prevalence of $\mathrm{CB}$, compare the prevalence between sex and correlate its prevalence with the occurrence of sinusitis. Coronal and axial sections were prepared and investigated in our study then were analyzed in the bone window and were interpreted by the same observer. 

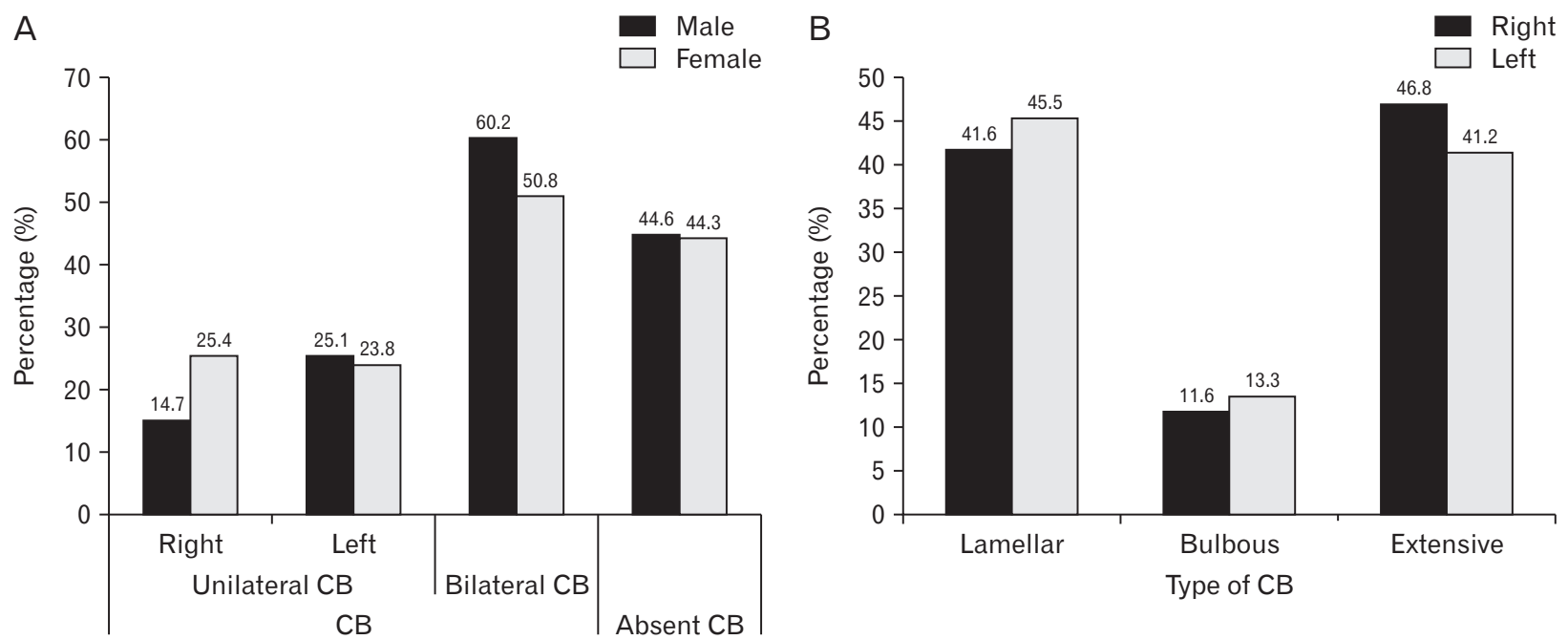

Fig. 2. Relations between CB, side and sex. Values are presented as percentages. (A) Relation between the incidence of $C B$, side and sex. $C B$ vs. absent $\mathrm{CB}$ according to sex chi-square $P$-value $=0.912$; unilateral $\mathrm{CB}$ vs. bilateral $\mathrm{CB}$ according to sex chi-square $P$-value $=0.041$, right $\mathrm{CB}$ vs. left $\mathrm{CB}$ according to sex chi-square $P$-value $=0.033$, right $\mathrm{CB}$ vs. bilateral $\mathrm{CB}$ according to sex chi-square $P$-value $=0.003$ and left $\mathrm{CB}$ vs. bilateral $\mathrm{CB}$ according to sex chi-square $P$-value $=0.604$. (B) Relation between the different types of $\mathrm{CB}$ and the side. Types of $\mathrm{CB}$ according to the side chisquare $P$-value $=0.453$. CB, concha bullosa.
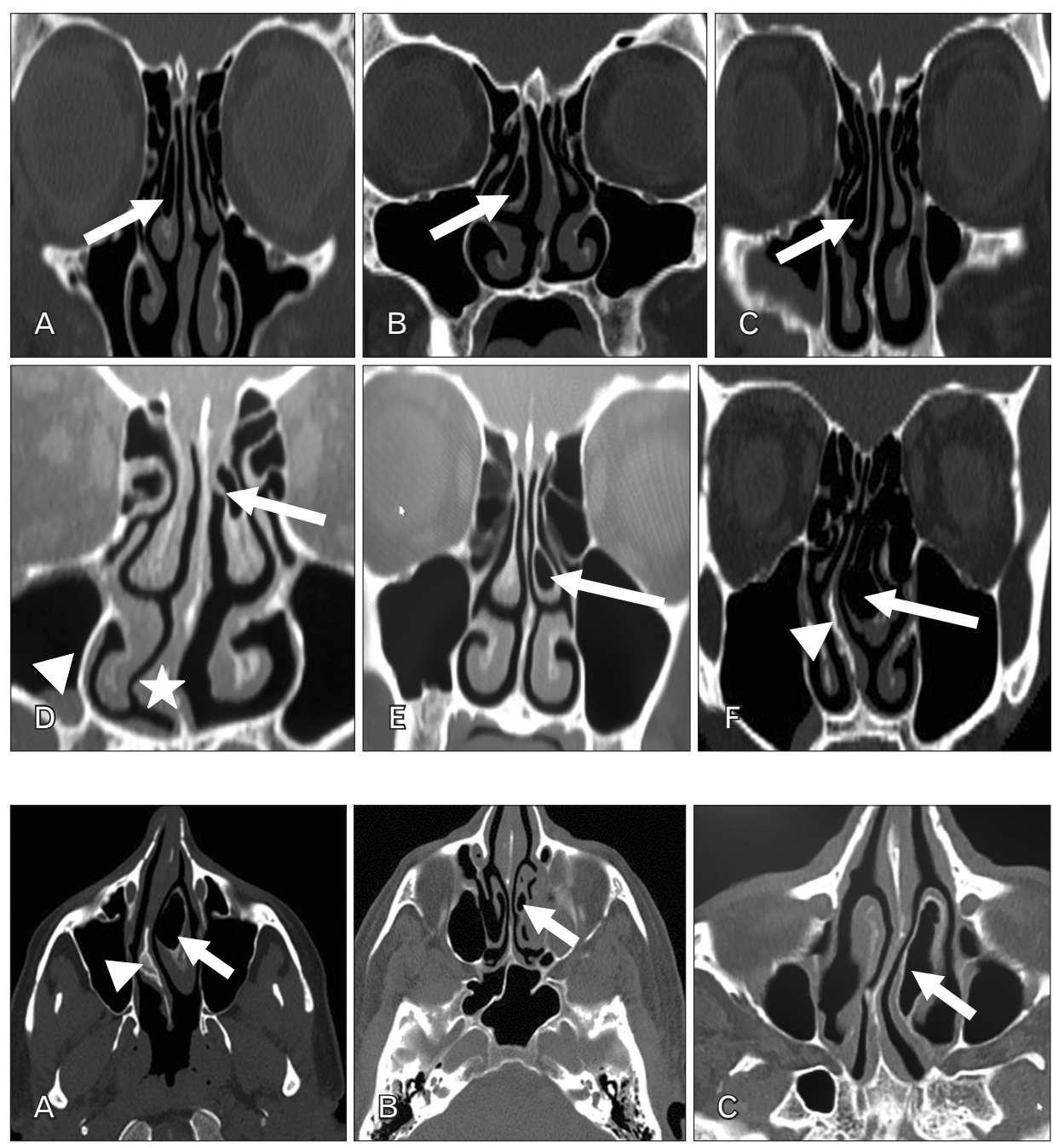

Fig. 3. Different types of unilateral concha bullosa $(\mathrm{CB})$ shown by coronal computed tomography images. (A) Right lamellar type CB (arrow). (B) Right bulbous CB (arrow). (C) Right extensive CB (arrow). (D) Left lamellar $\mathrm{CB}$ (arrow) with right maxillary sinusitis (arrowhead) and deviated nasal septum to right (asterisk). (E) Left bulbous CB (arrow). (F) Left extensive CB (arrow), with nasal septum deviation having a convexity to the right side (arrowhead).

Fig. 4. Different types of unilateral concha bullosa $(\mathrm{CB})$ shown by axial computed tomography images. (A) Left large bulbous CB (arrow) with severe deviation of the nasal septum convexity to the right side (arrowhead). (B) Left lamellar CB (arrow). (C) Left extensive $\mathrm{CB}$ (arrow). 


\section{Statistical analysis}

The software program (Statistical Package for Social Sciences SPSS $^{\circledR}$ ver. 20.0; IBM Corp., Armonk, NY, USA) was used to analyze our data. Categorical variables were presented in numbers and percentages (\%). Qualitative variables were correlated using chi-square test. If chi-square $P$-value was $\leq 0.05$, it was considered to be significant.

\section{Results}

In the present study, the patients aged between 18 and 79 years old with a mean of $34.5 \pm 10.7$ years. $C B$ was found in $488(55.5 \%)$ cases. It was uniformly prevalent in both males and females ( $P=0.912)$ (Fig. 2A). Regarding the different
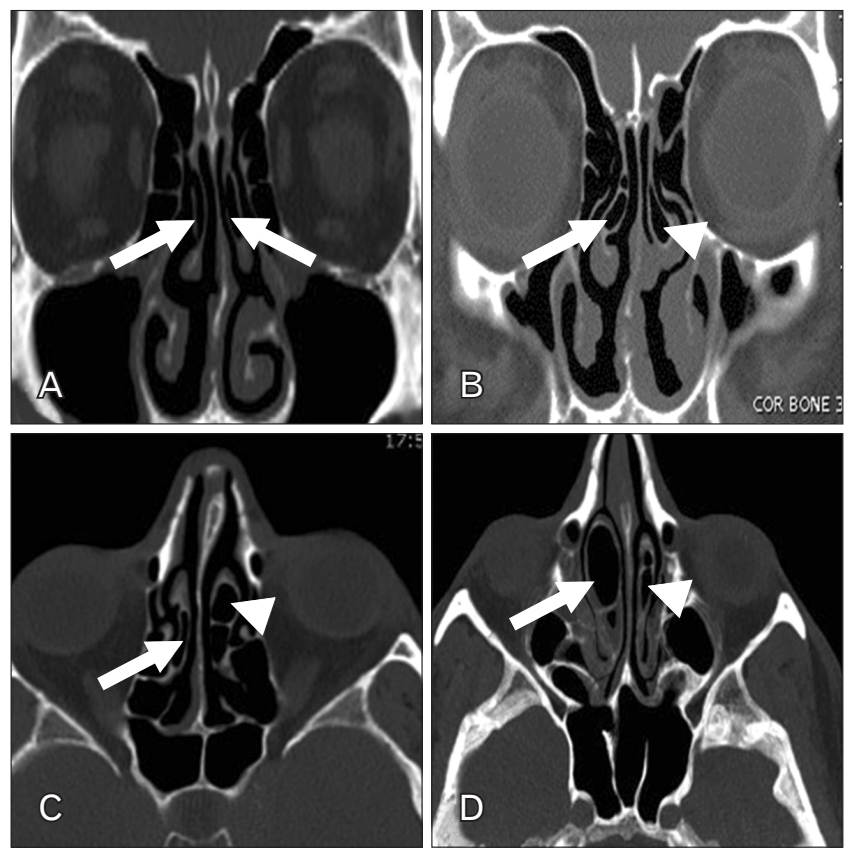

Fig. 5. Different types of bilateral concha bullosa $(\mathrm{CB})$ shown by coronal (A, B) and axial (C, D) computed tomography images. (A) Bilateral lamellar type of CB (arrows). (B) Right lamellar (arrow) and left bulbous CB (arrowhead). (C) Right lamellar (arrow) and left extensive CB (arrowhead). (D) Right extensive CB (arrow) and left bulbous type (arrowhead). types of $\mathrm{CB}$, the most frequent observed type was extensive $\mathrm{CB}$ followed in close succession by lamellar $\mathrm{CB}$, while only (12.5\%) of the conchae were of bulbous type (Fig. 2B). The prevalence of bilateral $\mathrm{CB}$ was more frequent as compared to the unilateral cases, with statistically significant difference $(P=0.041)$. Overall, the prevalence of left $\mathrm{CB}$ was more frequent as compared to the right with statistically significant difference ( $P=0.033$ ) (Figs. 2A, 3-5).

The most common type of $\mathrm{CB}$ in the right side was extensive $\mathrm{CB}$ whereas in the left side, lamellar $\mathrm{CB}$ was the most frequent. The most common type of $\mathrm{CB}$ among males was extensive CB whereas in females was lamellar CB; however there was no statistical difference between the frequency of different types of CB according to the sex (Figs. 3-6).

Among the studied groups, sinusitis was observed in 234 (48.0\%) of CB patients. The males were more affected by sinusitis than females, with no statistically significant difference $(P=0.747)$ (Table 1). Out of 234 patients with sinusitis, ethmoidal sinusitis was the most predominant type encountered in this study (Fig. 7A) followed by the maxillary sinusitis (Fig. 7B). Lower prevalence for frontal (Fig. 7C) then sphenoidal sinusitis (Fig. 7D) was associated with CB (Table 2). The

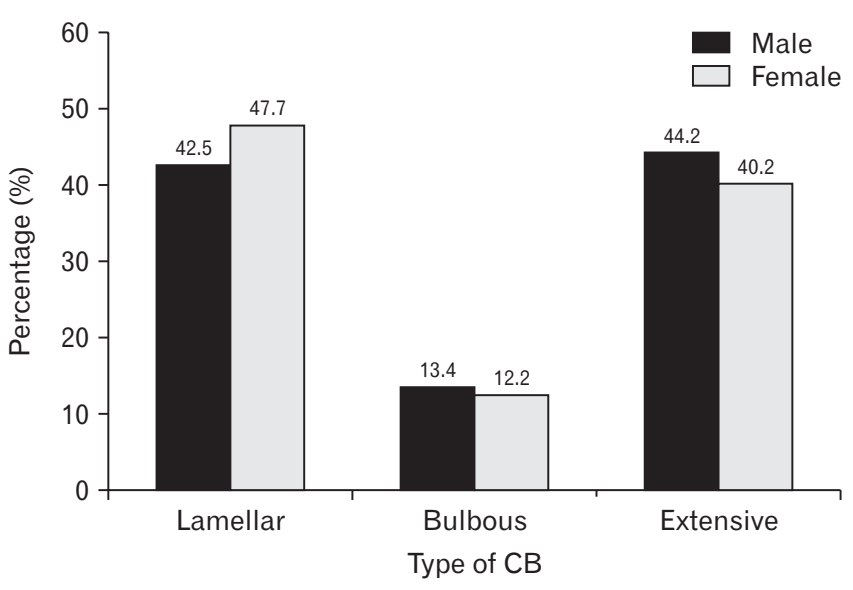

Fig. 6. Relation between different types of $\mathrm{CB}$ and sex. Values are presented as number (percentage). Types of $\mathrm{CB}$ according to the sex chi-square $P$-value $=0.693$. CB, concha bullosa.

Table 1. Relation among the incidence of sinusitis, concha bullosa (CB), and sex

\begin{tabular}{|c|c|c|c|c|c|c|}
\hline \multirow{2}{*}{ Sex } & \multicolumn{2}{|c|}{ Sinusitis } & \multicolumn{2}{|c|}{ No sinusitis } & \multicolumn{2}{|c|}{ Total } \\
\hline & $\mathrm{CB}$ & Absent CB & $\mathrm{CB}$ & Absent $\mathrm{CB}$ & $\mathrm{CB}$ & Absent CB \\
\hline Male & $146(48.8)$ & $14(5.8)$ & $153(51.2)$ & $227(94.2)$ & $299(100)$ & 241 (100) \\
\hline Female & $88(46.6)$ & $9(6.0)$ & $101(53.4)$ & $141(94.0)$ & $189(100)$ & $150(100)$ \\
\hline Total & $234(48.0)$ & $23(5.9)$ & $254(52.0)$ & 368 (94.1) & $488(100)$ & $391(100)$ \\
\hline
\end{tabular}

Values are presented as number (\%). Presence or absence of sinusitis according to the sex chi-square $P$-value $=0.747$ and presence or absence of sinusitis according to the presence or absence of $\mathrm{CB}$ chi-square $P$-value $<0.001$. 
rest of the studied patients with involvement of more than three sinuses (pansinusitis) (Fig. 8) compromised 136 (36.4\%) patients (Table 2).

Regarding the correlation of $\mathrm{CB}$ with sinusitis, sinusitis was more prevalent in cases having $\mathrm{CB}$ ( $48 \%$ of $\mathrm{CB}$ cases) than those had no CB (5.9\% of cases with no CB) with significant difference in-between $(P<0.001)$ (Table 1$)$. The most common type of $\mathrm{CB}$ among patients with sinusitis was extensive CB followed by the lamellar type (Table 2). According
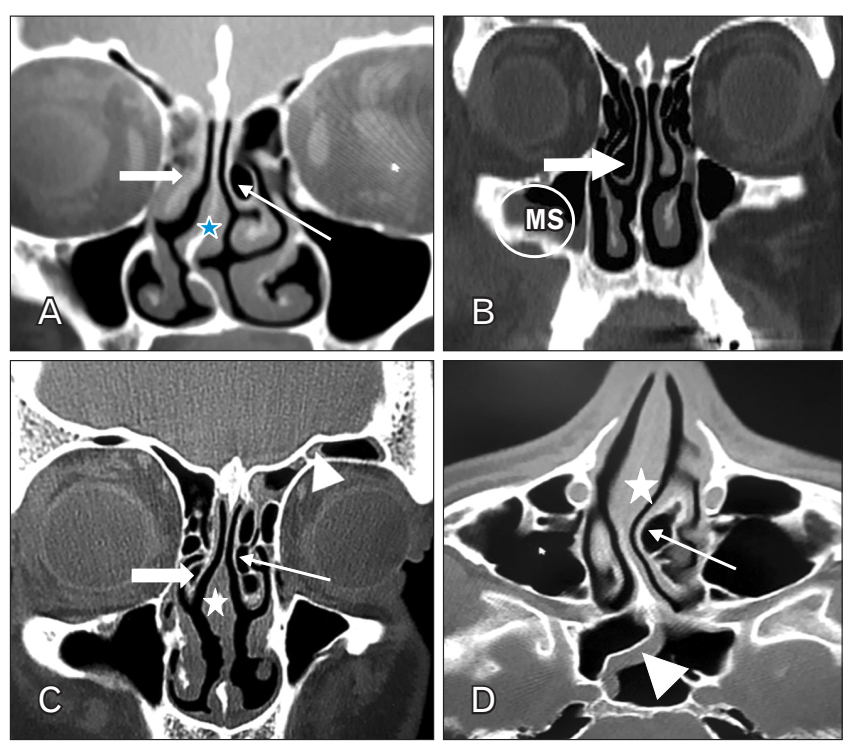

Fig. 7. Different types of concha bullosa (CB) associated with different types of sinusitis shown by coronal $(\mathrm{A}, \mathrm{C})$ and axial (D) computed tomography images. (A) Left bulbous CB (thin arrow), with deviated nasal septum (asterisk) to the right and solitary right ethmoidal sinusitis (thick arrow). (B) Moderate sized right extensive CB (arrow) with ipsilateral mucosal thickening in the maxillary sinus (MS). (C) Left extensive CB (thin arrow) with mild left frontal mucosal thickening (sinusitis) (arrowhead) associated with nasal septum deviation to right side (asterisk). Right bulbous $\mathrm{CB}$ is also noted (thick arrow). (D) Left bulbous CB (arrow) associated with sphenoid sinusitis (arrowhead) and deviated nasal septum to right side (asterisk). to the side of $\mathrm{CB}$, sinusitis was more prevalent in bilateral $\mathrm{CB}$ cases $(74.7 \%)$ than in unilateral CB ones $(25.3 \%)$ with a significant difference in-between $(P<0.001)$, however there was no significant difference between the incidence of sinusitis between right and left CB cases $(P=0.485)$ (Table 3).

\section{Discussion}

Prevalence of CT helps the otolaryngologists and dentists for better and easy distinguishing the anatomical variations and pathological conditions of the nasal cavity and adjacent paranasal sinuses. Previous radiographic methods were less successful in detecting anomalies in the sinuses. CT scans can easily recognize mucosal inflammation, apparently making this radiographic technique the ideal for precisely assessing the nasal cavity and paranasal sinuses [1].

The middle turbinate acts as an inspired air moisturizer. It aids to laminate flow of the inspired air then pushes it upwards toward the epithelium of olfactory mucosa [11]. A pneumatized middle turbinate, $\mathrm{CB}$; may be unilateral or
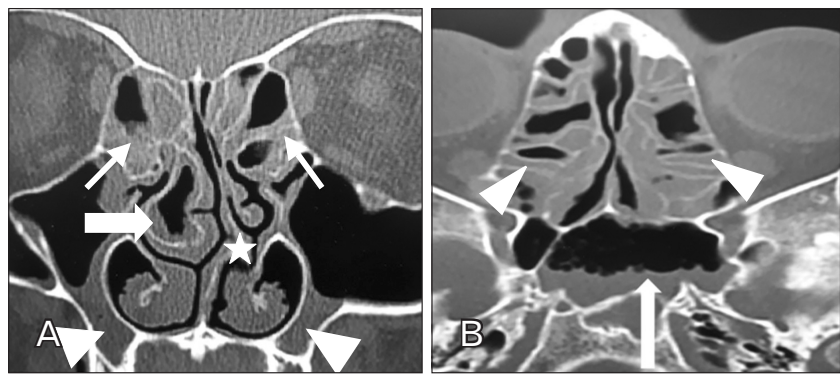

Fig. 8. Pansinusitis in the same subject having concha bullosa (CB) shown by coronal (A) and axial (B) computed tomography images. (A) Right bulbous CB (thick arrow) with partial opacification denoting infected $\mathrm{CB}$, bilateral ethmoidal (thin arrows) and bilateral maxillary sinusitis (arrowheads). Deviated nasal septum to left is also noted (asterisk). (B) Sphenoid (arrow) and bilateral ethmoidal (arrowheads) sinusitis.

Table 2. Association between the types of sinusitis and different type of concha bullosa (CB)

\begin{tabular}{|c|c|c|c|c|c|c|c|c|c|}
\hline \multirow{3}{*}{ Type of sinusitis } & \multicolumn{6}{|c|}{$\mathrm{CB}$} & \multirow{2}{*}{\multicolumn{2}{|c|}{ Absent CB }} & \multirow{3}{*}{ Total } \\
\hline & \multicolumn{2}{|c|}{ Lamellar } & \multicolumn{2}{|c|}{ Bulbous } & \multicolumn{2}{|c|}{ Extensive } & & & \\
\hline & Male & Female & Male & Female & Male & Female & Male & Female & \\
\hline Ethmoidal sinusitis & $21(33.9)$ & $11(27.5)$ & $6(20.0)$ & $6(31.6)$ & $35(28.0)$ & $17(23.0)$ & $4(28.6)$ & $3(30.0)$ & $103(27.5)$ \\
\hline Maxillary sinusitis & $15(24.2)$ & $8(20.0)$ & $9(30.0)$ & $5(26.3)$ & $30(24.0)$ & $17(23.0)$ & $5(35.7)$ & $3(30.0)$ & $92(24.6)$ \\
\hline Frontal sinusitis & $3(4.8)$ & $3(7.5)$ & $2(6.7)$ & $0(0)$ & $6(4.8)$ & $5(6.8)$ & $3(21.4)$ & $1(10.0)$ & $23(6.2)$ \\
\hline Sphenoidal sinusitis & $2(3.2)$ & $3(7.5)$ & $1(3.3)$ & $2(10.5)$ & $5(4.0)$ & $3(4.1)$ & $2(14.3)$ & $2(20.0)$ & $20(5.4)$ \\
\hline Pansinusitis & $21(33.9)$ & $15(37.5)$ & $12(40.0)$ & $6(31.6)$ & $49(39.2)$ & $32(43.2)$ & $0(0.0)$ & $1(10.0)$ & $136(36.4)$ \\
\hline Total & $62(100)$ & $40(100)$ & $30(100)$ & $19(100)$ & $125(100)$ & $74(100)$ & $14(100)$ & $10(100)$ & $374(100)$ \\
\hline
\end{tabular}

Values are presented as number (\%). Types of sinusitis according to the sex chi-square $P$-value $=0.781$, types of sinusitis according to presence or absence of $\mathrm{CB}$ chi-square $P$-value $<0.001$ and type of sinusitis according to the type of CB chi-square $P$-value $=0.959$. 
Table 3. Relation between the incidence of types of sinusitis and the side of concha bullosa (CB)

\begin{tabular}{|c|c|c|c|c|}
\hline \multirow{2}{*}{ Sinusitis } & \multicolumn{2}{|c|}{ Unilateral CB } & \multirow{2}{*}{ Bilateral CB } & \multirow{2}{*}{ Total } \\
\hline & Right & Left & & \\
\hline \multicolumn{5}{|l|}{ Present } \\
\hline Ethmoidal & $21(21.9)$ & $17(17.7)$ & $58(60.4)$ & $96(100)$ \\
\hline Maxillary & $23(27.4)$ & $22(26.2)$ & 39 (46.4) & $84(100)$ \\
\hline Frontal & $7(36.8)$ & $4(21.1)$ & $8(42.1)$ & $19(100)$ \\
\hline Sphenoidal & $5(31.3)$ & $4(25.0)$ & $7(43.8)$ & $16(100)$ \\
\hline Pansinusitis & $37(27.4)$ & $37(27.4)$ & $61(45.2)$ & $135(100)$ \\
\hline Absent & $55(21.7)$ & $78(30.7)$ & $121(47.6)$ & $254(100)$ \\
\hline
\end{tabular}

Values are presented as number (\%). Presence or absence of sinusitis according to the side of $\mathrm{CB}$ chi-square $P$-value $<0.001$ (unilateral CB vs. bilateral $\mathrm{CB}$ $P$-value $<0.001$, right $\mathrm{CB}$ vs. left $\mathrm{CB} P$-value $=0.485$, right $\mathrm{CB}$ vs. bilateral $\mathrm{CB} P$-value $=0.009$ and left $\mathrm{CB}$ vs. bilateral $\mathrm{CB} P$-value $<0.001$.

Table 4. Prevalence of concha bullosa (CB) in the previous studies

\begin{tabular}{|c|c|c|c|c|c|c|c|c|c|}
\hline \multirow{2}{*}{ Author } & \multirow[b]{2}{*}{ Country } & \multirow[b]{2}{*}{ Method of assessment } & \multirow{2}{*}{\multicolumn{2}{|c|}{ Number (\%) }} & \multicolumn{2}{|c|}{ Sex } & \multicolumn{3}{|c|}{ Type of CB } \\
\hline & & & & & Male & Female & Lamellar & Bulbous & Extensive \\
\hline Present study & Saudi Arabia & Coronal and axial CT & 879 & $(55.52)$ & 55.4 & 55.8 & 43.6 & 12.5 & 44.0 \\
\hline Bolger et al. [1] & United States & Coronal CT & 202 & $(53.0)$ & - & - & 46.2 & 31.2 & 15.7 \\
\hline Pérez-Piñas et al. [14] & Spain & Coronal and axial CT & 110 & $(73.0)$ & - & - & - & - & - \\
\hline Smith et al. [15] & United States & Cone-beam CT & 883 & $(67.5)$ & 43.7 & 56.3 & - & - & - \\
\hline Anbiaee et al. [16] & Iran & Coronal and axial CT & 199 & (14.6) & 13.8 & 17.5 & - & - & - \\
\hline Kalaiarasi et al. [17] & India & Axial, coronal and Sagittal CT & 202 & $(31.7)$ & - & - & 22.2 & 28.3 & 49.5 \\
\hline Bahemmat and Hadian [18] & Iran & Cone-beam CT & 500 & (27.6) & 38.0 & 62.0 & - & - & - \\
\hline Stallman et al. [19] & United States & Coronal CT & 998 & $(44.0)$ & - & - & 42.0 & 44.0 & 13.0 \\
\hline Maru and Gupta [20] & India & Coronal and axial CT & 61 & $(42.6)$ & - & - & 42.3 & 27.0 & 30.7 \\
\hline Gupta et al. [21] & India & Axial, coronal and Sagittal CT & 69 & $(11.5)$ & - & - & 30.7 & - & - \\
\hline Al-Rawi et al. [22] & United Arab Emirates & Cone-beam CT & 106 & $(37.7)$ & 38.8 & 37.0 & - & - & - \\
\hline
\end{tabular}

CT, computed tomography.

bilateral. The anterior or posterior ethmoid cells are responsible for creation this pneumatization. The prevalence of $\mathrm{CB}$ ranges between $14.0 \%$ and $53.0 \%$ [12]. Except if the CB has a large size to block the nasal airway or the sinus ostia, it is overwhelmingly asymptomatic and is only seen by chance on CT scanning [13].

In the present study, the prevalence rate of $\mathrm{CB}$ was $55.5 \%$. This result is in agreement with the findings mentioned by Bolger et al. [1], however the prevalence in our study is less than the studies conducted by Pérez-Piñas et al. [14] and Smith et al. [15]. On contrast, a relatively lower prevalence rate of CB was recorded by Anbiaee et al. [16], Kalaiarasi et al. [17], Bahemmat and Hadian [18], Stallman et al. [19], Maru and Gupta [20], Gupta et al. [21], and Al-Rawi et al. [22]. The difference in prevalence between our population and Emirati people [22] may be due to wide range of numbers of the studied CT scans (879 in our study vs. 106 in Emirati people), furthermore the different type of the used CT scans in both studies (Table 4).

Regarding the various types of CB; lamellar concha is defined as vertical lamella pneumatization. Bulbous type is de- termined by pneumatization of bulbous part, and extensive type is characterized by pneumatization of both segments [7]. In the present study, the most frequent type observed was extensive type (44.0\%), followed in close succession by lamellar type (43.6\%), then bulbous type which was observed only in (12.5\%) of patients. Bolger et al. [1] reported that the incidence of CB of extensive type was (15.7\%), bulbous type was (46.2\%) and lamellar type was (31.2\%). In another study done by Stallman et al. [19] CB was found in $44.0 \%$ of the cases and was unilateral in $35.0 \%$ of patients, out of these conchae; $42.0 \%$ were lamellar, $44.0 \%$ were bulbous and $13.0 \%$ were extensive.

In the present study the prevalence of bilateral CB was $(55.5 \%)$ that was more frequent as compared to the unilateral cases $(44.5 \%)$ with statistically significant difference $(P=0.041)$. On the other hand, $\mathrm{CB}$ was found to be uniformly prevalent in both male and females (55.4\% and 55.8\%) respectively. The prevalence of left CB (24.6\%) was more frequent as compared to the right one (18.9\%) with statistically significant difference $(P=0.033)$. On the contrary, in an Indian study reported by Kalaiarasi et al. [17], out of the 202 
studied CT scans, the incidence of $\mathrm{CB}$ was $31.7 \%$. The $\mathrm{CB}$ was bilateral in 35 (54.7\%) cases and unilateral in 29 (45.3\%) cases. Out of 99 conchae, 54 were on the right side and 45 were on left side.

$\mathrm{CB}$ can imping on the infundibulum and ostium of maxillary, anterior ethmoid, and frontal sinuses causing a negative effect on their ventilation making them more prone to infection $[23,10]$. Also, there is a strong relationship between the incidence of $\mathrm{CB}$ and contralateral nasal septal deviation [1]. However, nasal septum deviation may be not as a result of $\mathrm{CB}$ pushing, rather this appears to be due to other as yet unknown developmental factors concerning a concha and the nasal septum [23]. Despite presence of CB and septal deviation are potential factors in the development of sinus disease, it is still an issue of argumentation [24]. Additionally, CB itself is a common cause of rhinogenic headache [10]. Thus, we evaluated the frequencies of presence of sinusitis in patients with or without CB.

Concerning sinusitis in our present study, the most frequently affected sinus was ethmoidal sinus (27.5\%), followed by involvement of the maxillary sinus (24.6\%) with lower prevalence for frontal and sphenoidal sinuses (6.2\%) and (5.4\%) respectively. Pansinusitis ( $>3$ affected sinuses) was noted in (36.4\%) of patients. This was in accordance with a study conducted by Bolger et al. [1] in Texas who reported that the most common affected sinus with $\mathrm{CB}$ was ethmoidal sinus (84.3\%), followed by maxillary sinus (77.7\%), while in other different studies carried out by Kinsui et al. [25] in São Paulo (Brazil), Bagri et al. [26] in New Delhi (India) and Van der Veken et al. [27] in Belgium, the most frequently involved sinus was maxillary sinus with a prevalence of $52.7 \%$, $57.3 \%$ and $63 \%$ respectively. In another study performed by Mamatha et al. [8] in India, the most common involved sinus was maxillary sinus (67.5\%), followed by ethmoidal sinus (32.5\%) and frontal sinus (25.0\%).

In the current study, the incidence of sinusitis was highly linked to the presence of CB. Sinusitis was more present in CB patients $(48.0 \%)$ than in cases of absence of $\mathrm{CB}(5.9 \%)$ with a significant difference in-between $(P<0.001)$. Some reports had proved the relationship between the presence of the $\mathrm{CB}$ and sinusitis, however other studies had concluded no direct relation in-between. In a study carried out by Stallman et al. [19], 72.0\% of patients with a CB had sinusitis, however; $78.0 \%$ of patients had sinusitis without $\mathrm{CB}$, they confirmed that there is no statistical association between the rhinosinusitis on either side and presence of unilateral or dominant
CB. Furthermore, Javadrashid et al. [28] had reported that there is no significant relationship between the presence of $\mathrm{CB}$ and chronic sinusitis. Conversely, Rajashree et al. [29] found a statistically significant relationship between the $\mathrm{CB}$ and ipsilateral sinusitis. Also, de Araújo Neto et al. [30] suggested that a large sized CB may occlude the ostia leading to sinusitis.

In the present study, the most common type of $\mathrm{CB}$ among patients with sinusitis in both sides was extensive CB. Several studies mentioned that the size of $\mathrm{CB}$ is a leading factor for the presence or absence of the sinusitis symptoms. Though, there was no significant association found between the size of the CB and chronic rhinosinusitis, many studies concluded that rhinosinusitis was more associated with the extensive type of CB [31]. In a study done by Unlü et al. [32], they reported that no association between $\mathrm{CB}$ and $\mathrm{OMC}$ disease. But they also confirmed that the bulbous $C B$ had more influence on OMC disease than other types of $\mathrm{CB}$. In a study carried out by Scribano et al. [33], 59.0\% of cases with chronic rhinosinusitis had CB. They confirmed that CB and many other anatomical variations (Uncinate process anomalies, Haller's cells and large bulla ethmoidalis) elevate the risk of incidence of the chronic sinusitis by approximating the osteomeatal mucosa in a close contact with the lining mucosa of the paranasal sinuses.

Probably the most diverse anatomical variations in the human body are that of the nasal cavities and paranasal sinuses [34]. As a one of these anatomical variations, CB prevalence has a wide range from $4.0 \%$ to $80.0 \%$ [35]. These anatomical variations are often ethnic based on genetic and environmental factors [36]. Furthermore, the wide range of numbers and types of the studied CT scans in different studies may also potentiate this discrepancy. For example, maxillary growth is highly affected by environmental factors such as abnormalities in the growth of paranasal bone, trauma, adenoid hypertrophy and nasal septum deviation $[37,38]$.

CT provides a good tool for sinonasal assessment, in addition to be superior to plane radiography and nasal endoscopy [36]. Traditional CT imaging may be as an axial, antero-posterior or coronal planes [39]. More recent, cone-beam computed tomography became used for maxillofacial imaging as it has many advantages over traditional CT, including higher image resolution, lower radiation dose, offers 3-dimensional images and lower cost of machine $[40,24]$. Thus, the type of used CT imaging machine and the planes used to assess sinonasal condition may affect the frequency of the discovered 
CB cases specially in mild ones. In addition, lamellar type of $\mathrm{CB}$ has not been incorporated by some authors in their studies which lowers their results about the frequency of CB [41].

In conclusion, the findings of the present study demonstrated that $\mathrm{CB}$ is prevalent in both males and females among Saudi population (55.4\% and 55.7\%) respectively. The prevalence of bilateral CB (55.5\%) is more frequent as compared to the unilateral (44.5\%) cases. The most frequent type observed is extensive CB (44.0\%). Sinusitis is prevalent in patients with CB (48.0\%) more than those have no CB (5.9\%), with the most common type of $\mathrm{CB}$ among patients with sinusitis is the extensive type.

\section{ORCID}

Wael Amin Nasr El-Din:

https://orcid.org/0000-0003-3673-990X

Gisma Ahmed Madani:

https://orcid.org/0000-0001-9176-3633

Islam Omar Abdel Fattah:

https://orcid.org/0000-0001-9398-9847

Esmat Mahmoud: https://orcid.org/0000-0002-1143-5152

Asmaa S. Essawy: https://orcid.org/0000-0002-9914-3372

\section{Author Contributions}

Conceptualization: GAM, WANED. Data acquisition: GAM, WANED, ASE. Data analysis or interpretation: IOAF, GAM, WANED, EM. Drafting of the manuscript: ASE, EM, WANED, GAM. Critical revision of the manuscript: WANED, ASE, IOAF. Approval of the final version of the manuscript: all authors.

\section{Conflicts of Interest}

No potential conflict of interest relevant to this article was reported.

\section{References}

1. Bolger WE, Butzin CA, Parsons DS. Paranasal sinus bony anatomic variations and mucosal abnormalities: CT analysis for endoscopic sinus surgery. Laryngoscope 1991;101(1 Pt 1):56-64.

2. Subramanian S, Lekhraj Rampal GR, Wong EF, Mastura S, Razi A. Concha bullosa in chronic sinusitis. Med J Malaysia 2005;60:535-9.

3. Hatipoğlu HG, Cetin MA, Yüksel E. Concha bullosa types: their relationship with sinusitis, ostiomeatal and frontal recess disease. Diagn Interv Radiol 2005;11:145-9.

4. Flint P, Haughey B, Lund V, Niparko J, Robbins K, Thomas J, Lesperance M. Cummings otolaryngology: head \& neck surgery. 6th ed. Philadelphia: Elsevier/Saunders; 2015. p. 658-78.

5. Tonai A, Baba S. Anatomic variations of the bone in sinonasal CT. Acta Otolaryngol Suppl 1996;525:9-13.

6. Al-Qudah MA. Anatomical variations in sino-nasal region: a computer tomography (CT) study. J Med J 2010;44:290-7.

7. Stammberger H, Hawke M. Essentials of endoscopic sinus surgery. 2nd ed. St. Louis: Mosby; 1993. p. 1-108.

8. Mamatha H, Shamasundar NM, Bharathi MB, Prasanna LC. Variations of ostiomeatal complex and its applied anatomy: a CT scan study. Indian J Sci Technol 2010;3:904-7.

9. Cukurova I, Yaz A, Gumussoy M, Yigitbasi OG, Karaman Y. A patient presenting with concha bullosa in another concha bullosa: a case report. J Med Case Rep 2012;6:87.

10. Ahmed EA, Hanci D, Üstün O, Aydogdu I, Özdemir E, Karaketir S, Uyar Y, Kumral TL. Surgical techniques for the treatment of concha bullosa: a systematic review. Otolaryngol Open J 2018;4:9-14.

11. Cohen SD, Matthews BL. Large concha bullosa mucopyocele replacing the anterior ethmoid sinuses and contiguous with the frontal sinus. Ann Otol Rhinol Laryngol 2008;117:15-7.

12. Okuyucu S, Akoğlu E, Dağli AS. Concha bullosa pyocele. Eur Arch Otorhinolaryngol 2008;265:373-5.

13. Al-Sebeih KH, Bu-Abbas MH. Concha bullosa mucocele and mucopyocele: a series of 4 cases. Ear Nose Throat J 2014;93:2831.

14. Pérez-Piñas, Sabaté J, Carmona A, Catalina-Herrera CJ, Jiménez-Castellanos J. Anatomical variations in the human paranasal sinus region studied by CT. J Anat 2000;197(Pt 2):221-7.

15. Smith KD, Edwards PC, Saini TS, Norton NS. The prevalence of concha bullosa and nasal septal deviation and their relationship to maxillary sinusitis by volumetric tomography. Int J Dent 2010;2010:404982.

16. Anbiaee N, Khodabakhsh R, Bagherpour A. Relationship between anatomical variations of sinonasal area and maxillary sinus pneumatization. Iran J Otorhinolaryngol 2019;31:229-34.

17. Kalaiarasi R, Ramakrishnan V, Poyyamoli S. Anatomical variations of the middle turbinate concha bullosa and its relationship with chronic sinusitis: a prospective radiologic study. Int Arch Otorhinolaryngol 2018;22:297-302.

18. Bahemmat N, Hadian H. The frequency of nasal septal deviation and concha bullosa and their relationship with maxillary sinusitis based on CBCT finding. Int J Med Res Health Sci 2016;5:152-6.

19. Stallman JS, Lobo JN, Som PM. The incidence of concha bullosa and its relationship to nasal septal deviation and paranasal sinus disease. AJNR Am J Neuroradiol 2004;25:1613-8.

20. Maru YK, Gupta V. Anatomic variations of the bone in sinonasal C.T. Indian J Otolaryngol Head Neck Surg 2001;53:123-8.

21. Gupta AK, Gupta B, Gupta N, Tripathi N. Computerized tomography of paranasal sinuses: a roadmap to endoscopic sur- 
gery. Clin Rhinol Int J 2012;5:1-10.

22. Al-Rawi NH, Uthman AT, Abdulhameed E, Al Nuaimi AS, Seraj Z. Concha bullosa, nasal septal deviation, and their impacts on maxillary sinus volume among Emirati people: a cone-beam computed tomography study. Imaging Sci Dent 2019;49:45-51.

23. Tiwari R, Goyal R. Role of concha bullosa in chronic rhinosinusitis. Indian J Otolaryngol Head Neck Surg 2019;71:128-31.

24. Ahmed DF. Prevalence and correlation of nasal septum deviation, concha bullosa and maxillary sinusitis in a group of adult Egyptian population: a retrospective CBCT study. Egypt Dent J 2020;66:143-52.

25. Kinsui MM, Guilherme A, Yamashita HK. Anatomical variations and sinusitis: a computed tomographic study. Rev Bras Otorrinolaringol 2002;68:645-52.

26. Bagri N, Kavirajan K, Chandra R, Agarwal Y, Gupta N, Mandal S. Nasal septal angle deviation: effect on lateral wall in nasal obstruction. Int J Res Med Sci 2019;7:90-5.

27. Van der Veken P, Clement PA, Buisseret T, Desprechins B, Kaufman L, Derde MP. [CAT-scan study of the prevalence of sinus disorders and anatomical variations in 196 children]. Acta Otorhinolaryngol Belg 1989;43:51-8. Dutch.

28. Javadrashid R, Naderpour M, Asghari S, Fouladi DF, Ghojazadeh M. Concha bullosa, nasal septal deviation and paranasal sinusitis; a computed tomographic evaluation. B-ENT 2014;10:291-8.

29. Rajashree, Ali FA, Deepthi P, Viswanatha B. Impact of concha bullosa on osteomeatal complex drainage and septal deviation. Res Otolaryngol 2018;7:1-4.

30. de Araújo Neto SA, de Sá Leite Martins P, Souza AS, Baracat ECE, Nanni L. The role of osteomeatal complex anatomical variations in chronic rhinosinusitis. Radiol Bras 2006;39:22732.

31. Tunçyürek Ö, Eyigör H, Songu M. The relationship among concha bullosa, septal deviation and chronic rhinosinusitis. J
Med Updates 2013;3:1-7.

32. Unlü HH, Akyar S, Caylan R, Nalça Y. Concha bullosa. J Otolaryngol 1994;23:23-7.

33. Scribano E, Ascenti G, Loria G, Cascio F, Gaeta M. The role of the ostiomeatal unit anatomic variations in inflammatory disease of the maxillary sinuses. Eur J Radiol 1997;24:172-4.

34. Mokhasanavisu VJP, Singh R, Balakrishnan R, Kadavigere R. Ethnic variation of sinonasal anatomy on CT scan and volumetric analysis. Indian J Otolaryngol Head Neck Surg 2019;71(Suppl 3):2157-64.

35. Alshaikh N, Aldhurais A. Anatomic variations of the nose and paranasal sinuses in Saudi population: computed tomography scan analysis. Egypt J Otolaryngol 2018;34:234-41.

36. Gouripur K, Udaya Kumar M, Janagond AB, Elangovan S, Srinivasa V. Incidence of sinonasal anatomical variations associated with chronic sinusitis by CT scan in Karaikal, South India. Int J Otorhinolaryngol Head Neck Surg 2017;3:576-80.

37. Calvo-Henriquez C, Ruano-Ravina A, Martinez-Capoccioni G, Martins-Neves S, Mayo-Yáñez M, Alosilla-Sandoval S, Junquera-Olay S, Varela E. Is an increase in the depth of the olfactory fossa caused by excessive vertical facial growth? A radiological study. B-ENT 2020;16:25-30.

38. Sirik M, Inan I. Evaluation of the relationship between concha bullosa and nasal septum deviation with diameter of nasolacrimal duct. Ann Med Res 2019;26:209-12.

39. Fatterpekar GM, Delman BN, Som PM. Imaging the paranasal sinuses: where we are and where we are going. Anat Rec (Hoboken) 2008;291:1564-72.

40. Orhan K, Aksoy S, Oz U. CBCT imaging of paranasal sinuses and variations. In: Gendeh BS, editor. Paranasal Sinuses. London: IntechOpen; 2017. p. 57-77.

41. Wadhwa S, Sharma N, Garg U, Dutta P. Concha bullosa: types and relationship with chronic sinusitis. Int J Otorhinolaryngol Head Neck Surg 2017;3:482-5. 